\title{
Notes on the vocalizations of Cinereous Conebill (Conirostrum cinereum)
}

\section{Peter Boesman}

In the following we briefly analyze and compare voice of the three races of Cinereous Conebill (Conirostrum cinereum). We also try to quantify the extent of any vocal differences using the criteria proposed by Tobias et al. (2010), as a support for taxonomic review. We have made use of sound recordings available on-line from Xeno Canto (XC).

A comparison, illustrated with sonograms:

fraseri

Presumed dawn song

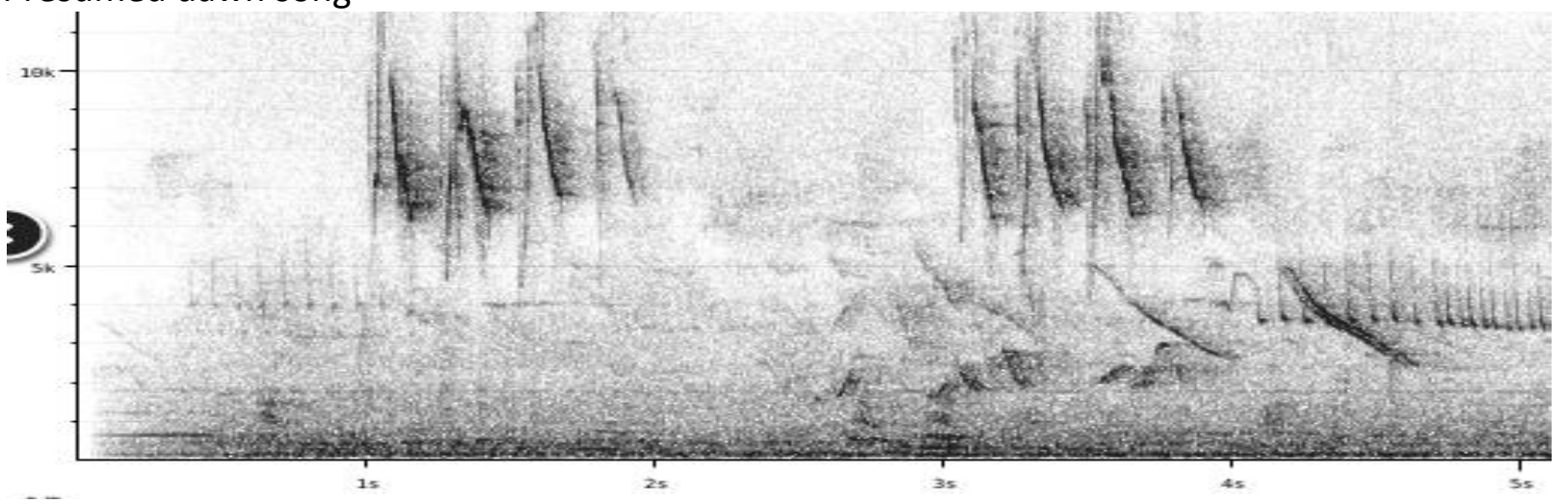

Day-time song
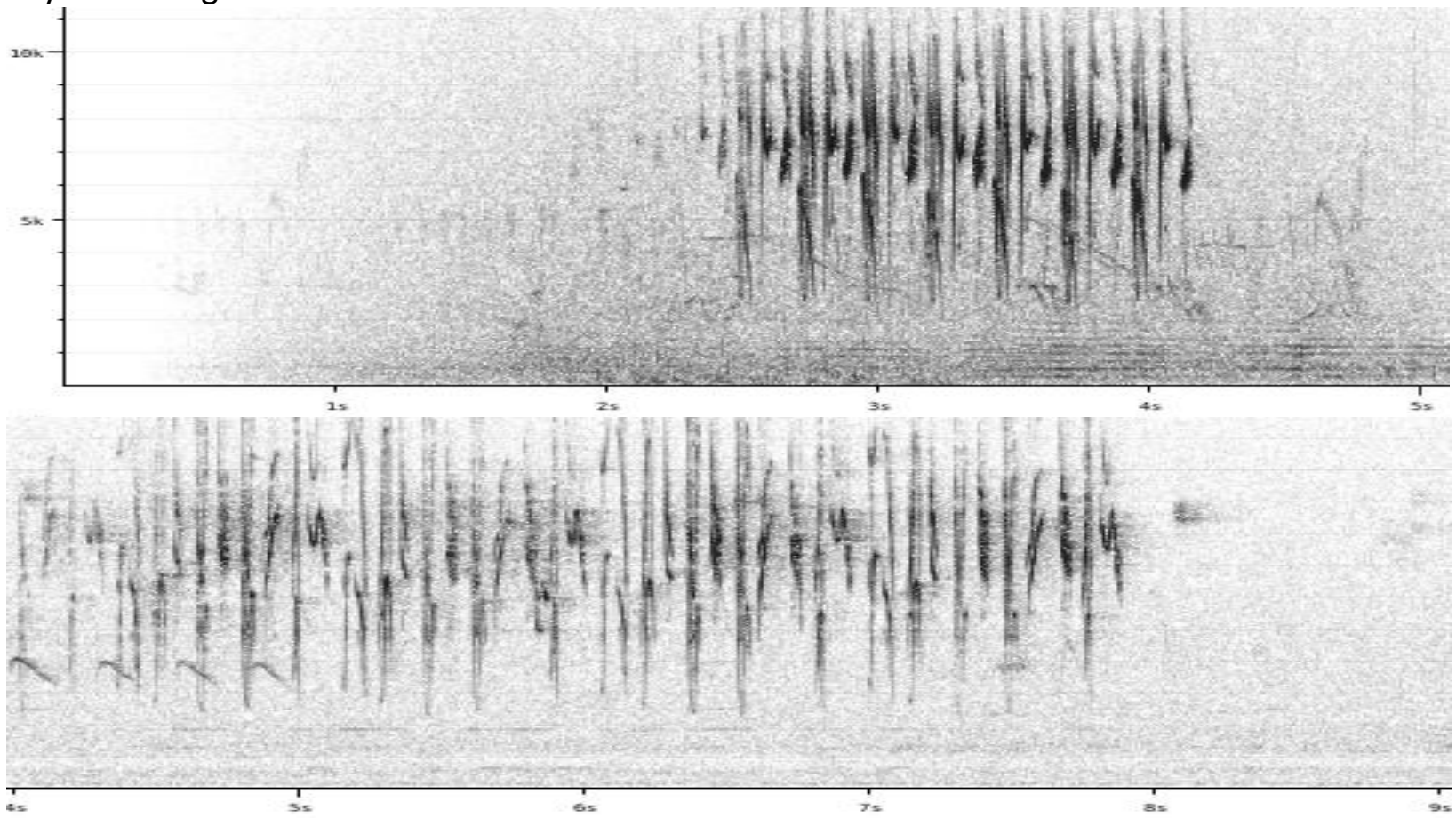


\section{HANDBOOK OF THE \\ BIRDSPIJUE WORLD}

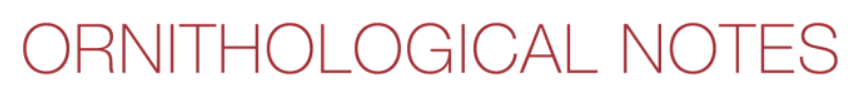

nominate

Day-time song
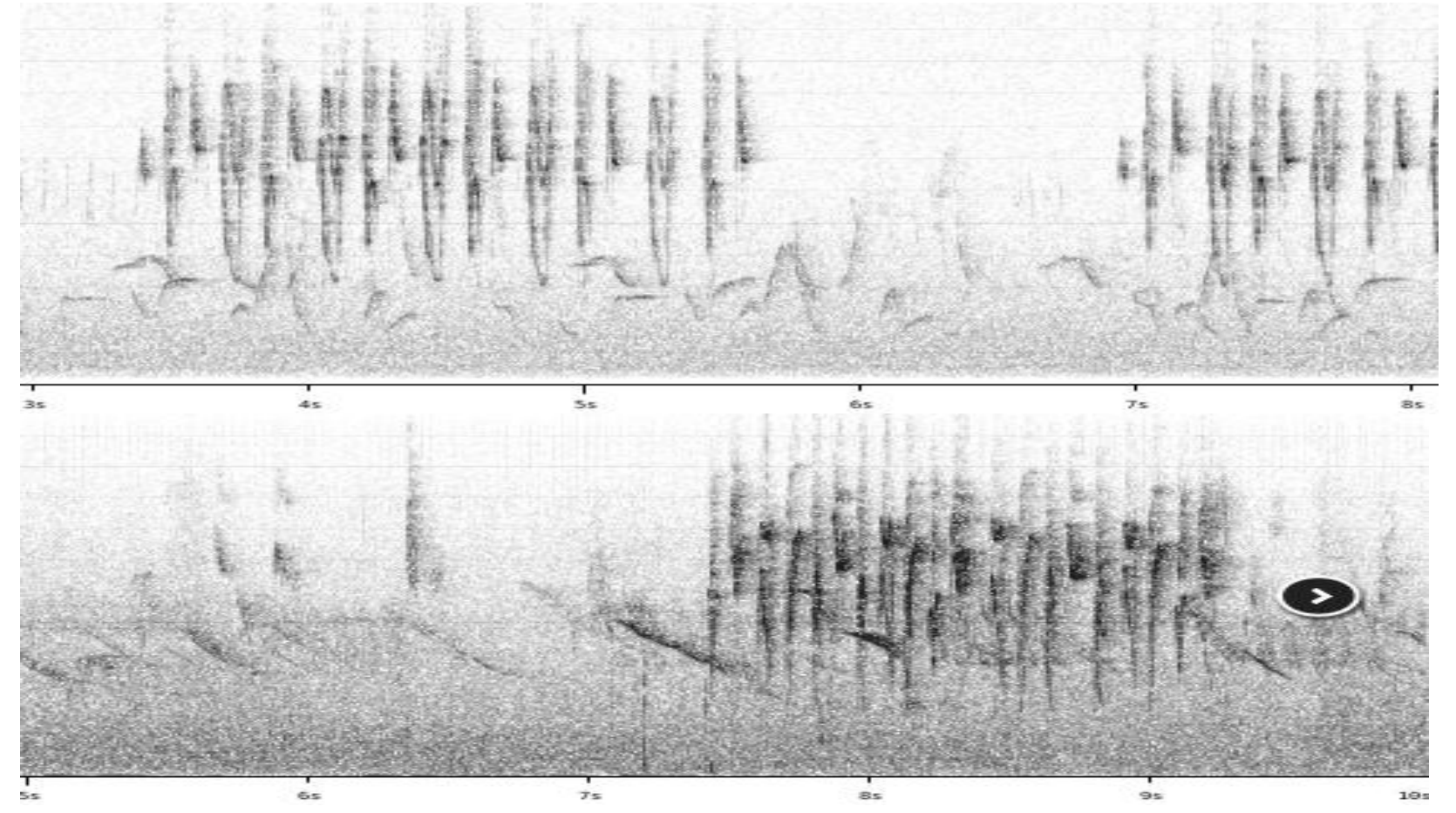

\section{littorale}

Day-time song

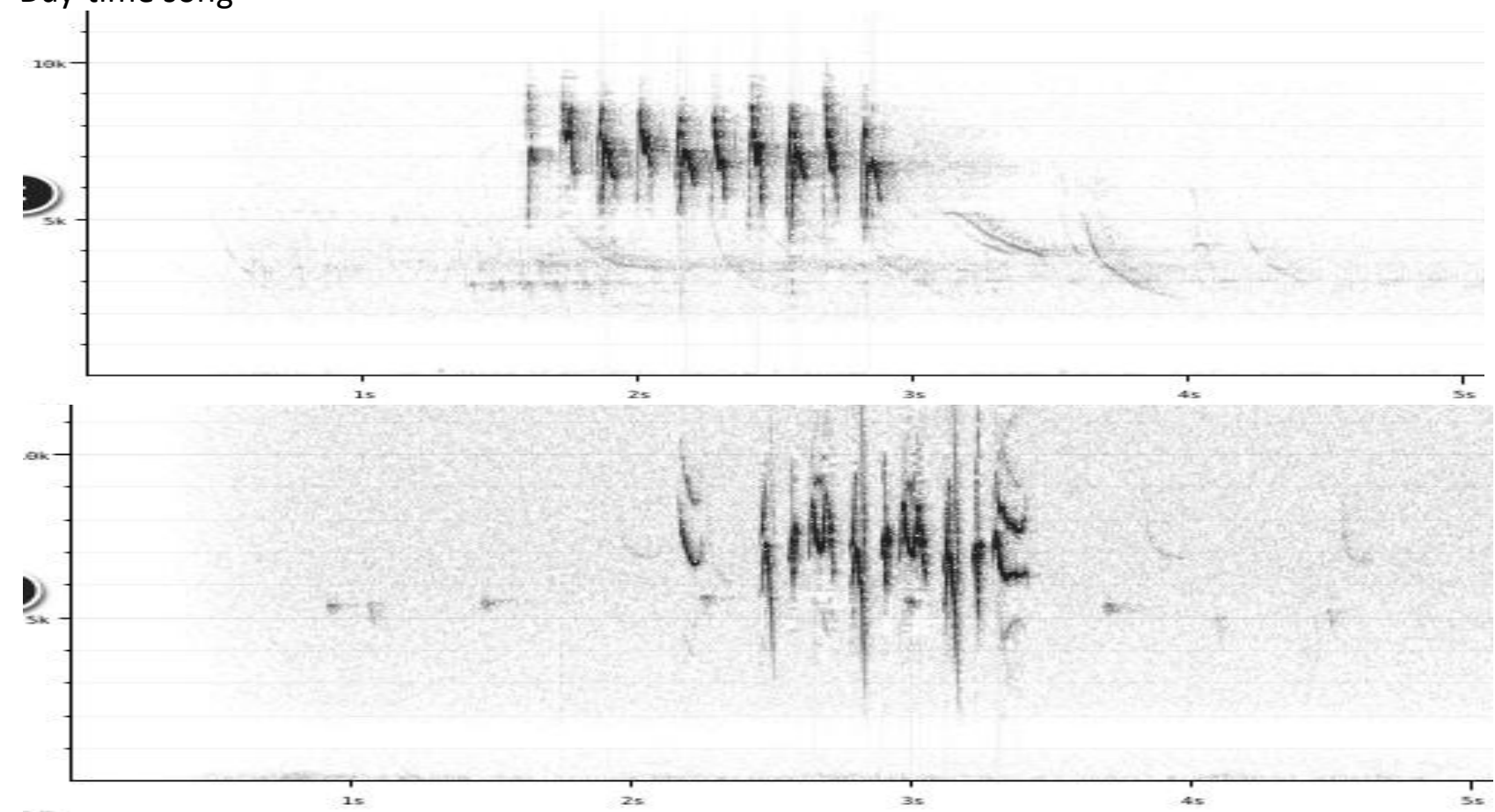




\section{HANDBOOK OF THE \\ BIRDSPF THE WORLD}

\section{ORNITHOLOGICAL NOTES}
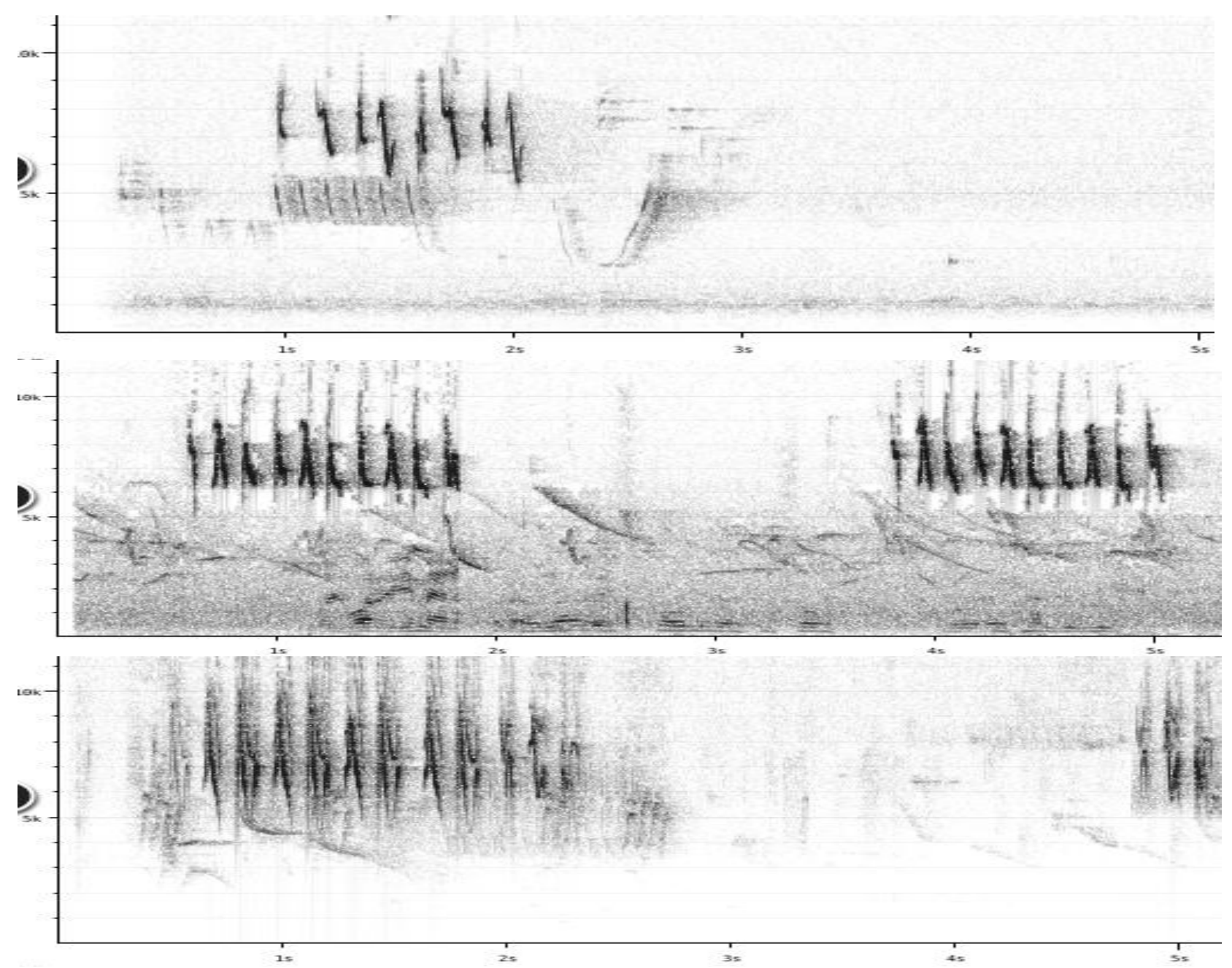

All races have a song which typically consists of a subphrase of 2-3 notes repeated, with some small differences between repeats.

Race litorale seems to have a day-time song with a much narrower freq. range (typically 3$5 \mathrm{kHz}$, vs. $7-9 \mathrm{kHz}$ ) and higher min. freq. (typically above $5 \mathrm{kHz}$ vs. above c. $2 \mathrm{kHz}$ ). Apparently some exceptions do occur however.

A more in depth analysis would be needed to uncover any additional differences, and would require a larger set of recordings than presently available.

This note was finalized on 29th June 2016, using sound recordings available on-line at that moment. We would like to thank in particular the sound recordists who placed their recordings for this species on XC: Israel Aragon, Nick Athanas, Peter Boesman, Allen Chartier, Sandra Espinoza, Alvaro Jaramillo, Niels Krabbe, Dan Lane, Mitch Leisinger, Sjoerd Mayer, John V Moore, Mike Nelson and Joseph Tobias.

\section{References}

Tobias, J.A., Seddon, N., Spottiswoode, C.N., Pilgrim, J.D., Fishpool, L.D.C. \& Collar, N.J. (2010). Quantitative criteria for species delimitation. Ibis 152(4): 724-746. 


\section{Recommended citation}

Boesman, P. (2016). Notes on the vocalizations of Cinereous Conebill (Conirostrum cinereum). HBW Alive Ornithological Note 387. In: Handbook of the Birds of the World Alive. Lynx Edicions, Barcelona. (retrieved from http://www.hbw.com/node/1252944 on 30 November 2016). 